\title{
Editorial of the First Issue of the International Journal of Learning Analytics and Artificial Intelligence for Education
}

\author{
https://doi.org/10.3991/ijai.v1i1.11073 \\ Jalal Nouri \\ Stockholm University, Stockholm, Sweden \\ jalal@i-jai.com
}

\begin{abstract}
In this editorial, the first issue of the International Journal of Learning Analytics and Artificial Intelligence for Education is presented. The Journal of Learning Analytics and Artificial Intelligence for Education is a peerreviewed, open access journal that aim to disseminate highest quality research in the field. The journal aims to increase knowledge and understanding of ways in which learning analytics and artificial intelligence can support and enhance education. The editorial presents the scope and fields of interest for the journal, and an overview of the articles published in the first issue.
\end{abstract}

Keywords - Inaugural issue, editorial, first issue, learning analytics, artificial intelligence, education

\section{Introduction}

We are honored to announce that we with this first issue launch the International Journal of Learning Analytics and Artificial Intelligence for Education.

In this post-industrial society, also called the information and knowledge society, we have witnessed that big data analytics and artificial intelligence already have become powerful and transformative tools in many fields such as business or medicine. Both these tools are rapidly developing and much indicates that they will continue to transform this post-industrial society. For some years now, researchers interested in education and learning around the world have also begun to realize the potential of these data analytics and artificial intelligence and intensified research around them. This interest has resulted in the emergence of the fast-growing and multi-disciplinary field of learning analytics, and intensified research on how artificial intelligence can support learning and teaching practices. This journal aims to support these research efforts by offering researchers a platform for bringing new results into focus as we engage in a fast-changing landscape with promises of an exciting future.

The journal of learning analytics and artificial intelligence for education is a peerreviewed, open access journal that aim to disseminate highest quality research in the field. The journal aims to increase knowledge and understanding of ways in which learning analytics and artificial intelligence can support and enhance education. As 
such the journal aims to connect researchers and other stakeholders that share a common interest in tracing learning, understanding learning and improving learning with the support of LA and AI. The journal covers all advances in learning analytics and artificial intelligence for education, including but not limited to the following topics: tools and methodologies for learning analytics and artificial intelligence for education, applications of learning analytics and artificial intelligence for education in real-world settings, theoretical perspectives on learning analytics and artificial intelligence for education.

Fields of interest include, but are not limited to:

- AI powered educational systems and tools

- Analyzing Learner's Activity, Engagement and Motivation

- Modelling Learning and Teaching in Different Environments (online, blended and physical environments)

- Evaluation and Development of Teaching Practices and Learning Designs

- Application of Machine Learning, Educational Data Mining, and Predictive Analytics

- Social Network Analysis and Network Modelling Tools

- Supporting and Developing Assessment and Feedback Practices

- Supporting Personalized and Adaptive Learning

- Analyzing and Improvement of Learning Organizations based on Data

- Development of new Methods and Theories

We invite authors to submit theoretical papers, empirical work, and more technical reports describing system development. Papers can be submitted as full papers, short papers, reports, and application notes.

\section{Overview of Papers in the First Issue}

This first issue presents a spectrum of diverse research articles written by members of the editorial team. The articles span research on learning analytics as well as artificial intelligence for education.

In the first jointly written article [1], we present a review of research conducted in seven European countries on the subject of data-driven development of education through learning analytics. More specifically, we examine the research efforts that have been conducted in the field of learning analytics in Austria, Denmark, Finland, Norway, Germany, Spain, and Sweden. The article reports on developed national policies, infrastructures and competence centers, as well as major research projects and developed research strands within the selected countries.

In the second article, Dirk Ifenthaler and Jane Yin-Kim Yau [2], investigate how ready higher education institutions are to adopt learning analytics by examining higher education stakeholders' views on learning analytics utilization to support study success. The authors present a number of barriers and challenges identified by 37 interviewed stakeholders. 
The third article, authored by Ulf Dalvad Berthelsen and Morten Tannert [3], also adopt the stakeholder perspective but examine in this case Danish case of ICT integration in primary and lower secondary school in order to study cases of emerging and at times conflicting stakeholder interests. The authors propose an ecological perspective on the role of analytics in education.

The fourth article, written by Miquel Conde-Gonzalez and Angel HernandezGarzia [4], explores the main issues involved in the assessment of learning activities that happen beyond the institution in non-formal or informal personal learning environments of individuals. The authors propose an open and flexible approach partly based on the application of learning analytics solutions to provide useful representations of learning processes.

In the fifth article by Josef Wachtler and Martin Ebner [5], the authors present an algorithm which schedules interactions in learning videos and live broadcastings based on the concept of a state machine. More specifically, they propose an adaptive and interactive video platform that also support the integration of learning analytics which can help us better understand how students interact with videos.

In the sixth article by Jeton Arifi, Markus Ebner and Martin Ebner [6], the authors present the development, testing and evaluation of an AI chatbot designed to help pupils in order to correct their spelling mistakes by providing correction proposals to them.

In the seventh article, Jalal Nouri, Ken Larsson and Mohammed Saqr [7], present a study in which they use learning analytics and machine learning in order to, one the one hand, identify factors that contribute to bachelor thesis completion and noncompletion, and on the other hand, predict completion and non-completion of thesis projects.

In the eighth and final article, Yu Yan, Simon Hooper and Shi Pu [8] present a study in which they have use learning analytics methods in order to evaluate the effectiveness of gamification and initial task difficulty on college student engagement with computer-based assessments.

\section{$3 \quad$ References}

[1] Nouri, J., Ebner, M., Ifenthaler, D., Saqr, M., Malmberg, J., Khalil, M., Viberg, O., Bruun, J., Conde-Gonzalez, M., Papamitsiou, Z. \& Berthelsen, U. (2019). Efforts in Europe for Data-Driven Improvement of Education - A review of learning analytics research in seven countries. International Journal of Learning Analytics and Artificial Intelligence for Education. 1(1).

[2] Ifenthaler, D. \& Yau, J. (2019). Higher Education Stakeholders' Views on Learning Analytics Policy Recommendations for Supporting Study Success. International Journal of Learning Analytics and Artificial Intelligence for Education. 1(1). https://doi.org/10.10 07/978-3-319-64792-0_4

[3] Berthelsen, U. \& Tannert, M. (2019). The Ecology of Analytics in Education: Stakeholder interests in data-rich educational systems. International Journal of Learning Analytics and Artificial Intelligence for Education. 1(1). 
[4] Conde-Gonzalez, M. \& Hernandez-Garzia, A. (2019). Data Driven Education in Personal Learning Environments - What about learning beyond the institution? International Journal of Learning Analytics and Artificial Intelligence for Education. 1(1).

[5] Wachtler, J. \& Ebner, M. (2019). Scheduling Interactions in Learning Videos: A State Machine Based Algorithm. International Journal of Learning Analytics and Artificial Intelligence for Education. 1(1).

[6] Arifi, J., Ebner, M., \& Ebner, M. (2019). Potentials of Chatbots for Spell Check among Youngsters. International Journal of Learning Analytics and Artificial Intelligence for Education. 1(1).

[7] Nouri, J., Larsson, K. \& Saqr, M. (2019). Bachelor thesis analytics: using machine learning to predict dropout and identify performance factors. International Journal of Learning Analytics and Artificial Intelligence for Education. 1(1).

[8] Yan, Y., Hooper, S. \& Pu, S. (2019). Gamification and Student Engagement with a Curriculum-based Measurement System. International Journal of Learning Analytics and Artificial Intelligence for Education. 1(1).

\section{Author}

Jalal Nouri is the Editor-in-Chief of iJAI, and is with Stockholm University, Sweden. Email: jalal@i-jai.com

Article submitted 2019-06-19. Resubmitted 2019-07-23. Final acceptance 2019-07-24. Final version published as submitted by the authors. 